\title{
Tensões entre o arquivo e o repertório: explorações da apropriação em certa poesia contemporânea brasileira
}

\section{Tensions between the archive and the repertore: explorations of the appropriation in a certain Brazilian contemporary poetry}

Luis Felipe Silveira de Abreu ${ }^{1}$

\section{Resumo:}

Este ensaio busca discutir algumas poéticas de apropriação em práticas contemporâneas da poesia brasileira. Com base na leitura dos livros Delírio de damasco, Um útero é do tamanho de um punho, Mais cotidiano que o cotidiano ${ }_{2}$ Livro das postagens e Sessão, delineamos um procedimento de cópia específico a este cenário, calcado no uso intensivo de citações, com um interesse singular pela transcrição de falas cotidianas. Nessa preocupação com a linguagem comum, identificamos a possibilidade de pensar uma escrita enredada pelos problemas conceituais do arquivo e do repertório. Por meio de tal jogo, somos levados a pensar como tal literatura reconfigura o gesto poético da apropriação, em uma reflexão tensiva sobre esses conceitos - e sobre a poesia mesma.

Palavras-chave: Poesia brasileira. Apropriação. Arquivo. Repertório 


\begin{abstract}
:
This essay seeks to discuss some poetics of appropriation in contemporary practices of Brazilian poetry. From the reading of the books Delírio de damasco, Um útero é do tamanho de um punho, Mais cotidiano que o cotidiano, Livro das postagens and Sessão, we outline a procedure of copy specific to this scenario, based on the intensive use of quotes, with a singular interest in the transcription of everyday speeches. In this concern with the common language, we identified the possibility of thinking about a writing caught up in the conceptual problems of the archive and the repertoire. Within this game, we are led to think about how such literature reconfigures the poetic gesture of appropriation in a tensive reflection on these concepts - and on poetry itself.
\end{abstract}

Keywords: Brazilian poetry. Appropriation. Archive. Repertoire.

Eram palavras que se soltavam da página e entravam em sua cabeça e saíam de sua cabeça sem o menor sentido. As frases altas e infindáveis dos ambulantes se misturavam com as do jornal, de tal maneira que eram frases também sem sentido para ele, eram frases das quais só recebia as palavras que eram ditas, nada mais, só as palavras, não o que com as palavras era vendido. Só recebia o peso das palavras (PUCHEU, 2013, p. 53)

E estas palavras, por sua vez, foram colhidas do texto Perfil parcial de um procedimento, escrito por Caio Meira, presente em Mais cotidiano que o cotidiano, de Alberto Pucheu (2013). Assim que nos parecem uma porta de entrada singular para discutir certo aspecto de certa poesia brasileira contemporânea, traçando as linhas pelas quais correrão nossas análises, apresentando o problema e sugerindo as hipóteses.

Comecemos pela confusão que esse breve texto introduz. Texto, dizemos; mas poderíamos chamá-lo poema? Assemelha-se também à prosa ou, no seu tom explicativo, a um escrito teórico. É bem essa 
impossibilidade de uma classificação rigorosa, clássica, que parece encarnar - e nos encaminha para investigar tal tendência como veio da produção atual. Análises semelhantes fazem Flora Süssekind (2013) e Florencia Garramuño (2014); aquela, falando da emergência de objetos verbais não identificados, produções anômalas que passam a experimentar com a dissolução de suas fronteiras literárias; esta, classificando tal poética como inespecífica e elencando seus procedimentos de decomposição, como a interpenetração de discursos artísticos e a invasão de vozes múltiplas e alheias.

Nesse último fio nos detemos, tomando-o à mão e deixandonos levar por ele. No desenvolvimento dessa molduração crítica, outros pesquisadores passam a identificar tal aposta na narrativa-coral (como a identifica Süssekind) enquanto traço singular e destacado dessa poética; lemos análises como as de Diana Klinger (2018) e Filipe Manzoni (2019), que identificam uma operação própria do não original nessa poética brasileira: o demarcado uso de citações, fragmentos alheios, peças verbais roubadas e transpostas.

Perfil parcial de um procedimento, escrito por Caio Meira é singular a essa perspectiva, como lemos já no seu título. ${ }^{2} \mathrm{O}$ texto, presente em um volume de Alberto Pucheu, diz-se escrito por outrem, o poeta Caio Meira, e sua narrativa (uma análise dos modos de composição de Pucheu, marcadas por diálogos e lembranças pessoais do narrador) confirma a "outridade" daquele fragmento, em meio a um livro "autoral" de Pucheu. Contudo, o método-Pucheu ali descrito diz respeito a seus "arranjos", colagens que mesclam frases ouvidas e lidas, colhidas ao acaso ou até solicitadas a amigos. Desse modo, o "escrito de Caio Meira" se tornaria

\footnotetext{
2 E, também, ao seu final, quando relaciona a poesia de Pucheu (a sua própria, seríamos capaz de dizer?) com o campo de estudos do não original instituído no campo de pesquisa literário, sobretudo a partir de referências estrangeiras: "Fico pensando o que, passado tanto tempo, as pessoas diriam hoje dele e dos outros que vieram antes e depois, como o que fez com as respostas que obteve quando escreveu para seu catálogo de endereço eletrônico pedindo que as pessoas enviassem as 15 primeiras frases que passassem por suas cabeças, num momento em que críticos como Marjorie Perloff e Kenneth Goldsmith, mesmo eles atrasados em relação a Alberto Pucheu, começam a falar desses procedimentos não criativos, de gênio não original e outros termos interessantes" (PUCHEU, 2013, p. 54).
} 
um "escrito de Pucheu" por excelência, por afirmar seu método poético particular tanto no conteúdo do discurso (uma descrição objetiva de tal método, cronológica e com referências bibliográficas), quanto na forma (um texto de outro, até mesmo assinado por outro, imiscuído em meio a uma reunião de poemas "próprios").

Esse jogo de espelhos, como tal, não encerra a leitura, senão multiplica suas reflexões: há, no circuito de apropriações entre Pucheu, Meira e as palavras tomadas em seu peso, das folhas dos jornais ou das ofertas de ambulantes, elementos para pensarmos um traço distintivo dessa apropriação, exposta por essa poesia fragmentária do contemporâneo. Exposto, também e sobretudo, esse jogo tenso, entre uma apropriação "de sujeito a sujeito" representada pelo texto de Meira enxertado por Pucheu e a apropriação do "cotidiano", efetuada por Pucheu nos seus arranjos. Essa noção de que há uma linguagem bruta no mundo, "as palavras que eram ditas, nada mais, só as palavras" (PUCHEU, 2013, p. 53), relaciona-se com um caráter singular do não original, que emerge como especificidade do inespecifico brasileiro: a disposição em apropriar a língua performada em público, entendida como a "linguagem comum".

Esse traço está inscrito já nas principais explorações do não criativo. No entanto, a poesia brasileira parece dobrar a aposta nesse tipo de apropriação - o que passa a desafiar o próprio conceito de apropriação, na medida em que se vale não de uma propriedade singular, identificável, mas de uma matéria pretensamente pública, disponível a quem quiser lê-la ou ouvi-la.

Tomamos aqui alguns textos exemplares de tal estratégia poética: Delírio de damasco, de Veronica Stigger (2012); Um útero é do tamanho de um punho, de Angélica Freitas (2012); Mais cotidiano que o cotidiano, de Alberto Pucheu (2013); e Livro das postagens, de Carlito Azevedo (2016). Com base em tais textos, gostaríamos, inicialmente, de delinear suas estratégias deapropriação; para, então, tendo em vista essa provisória 
tipologia, confrontá-la com as noções conceituais implicadas por tais gestos. Se os primeiros arranjos de Pucheu merecem o comentário de Caio Meira sobre uma invenção do "ele lírico" (PUCHEU, 2013, p. 53), gostaríamos de indagar no que implica a produção de um "eles lírico", a partir de um sujeito oculto - e quais as repercussões desses sujeitos inventados sobre a poesia de apropriação.

\section{Procedimentos de apropriação: o arquivamento do alheio}

Pensemos, de início, a "escrita de ouvido" de Delírio de Damasco: no livro, fruto de uma exposição realizada em 2010 (cf. STIGGER, 2013), Stigger reúne uma coleção de breves frases coletadas em conversas, próprias ou alheias, escutadas no cotidiano. Os trechos consistem, em sua maioria, em pequenas pérolas de intolerância, recortes de discursos violentos ou preconceituosos, que Stigger entrevê como expressão de uma força ulterior, a permear o espaço público. Essa motivação fica bastante clara na contracapa do volume: "Essas falas, justamente por nos chegarem fracionadas, em cacos ou lampejos, têm sempre um quê de enigma, sugerindo, ao ouvinte imaginoso, histórias potenciais, ficções embrionárias" (STIGGER, 2012. De tal modo, a reunião consistiria em uma "arqueologia da linguagem do presente" (STIGGER, 2012, grifo do autor).

Uma preocupação muito similar engendra os 3 poemas com o auxílio do Google, seção de Um útero é do tamanho de um punho, de Angélica Freitas (2012). Os três textos em questão foram construídos com a ferramenta de pesquisa do Google e seu mecanismo de preenchimento automático das frases, baseado nas buscas mais frequentes. Ao digitar os princípios de sentença "a mulher vai", "a mulher pensa" e "a mulher quer", Freitas recolhe as sugestões, expressões algorítmicas, metonímia digital para o banco de dados da ideologia comum.Não surpreendente, os textos 
resultam coalhados de misoginia: "a mulher quer ser amada / a mulher quer um cara rico / a mulher quer conquistar um homem / a mulher quer um homem / a mulher quer sexo" (FREITAS, 2012, p. 72).

Tal leitura preocupada com o presente, uma espécie de elaboração sobre o imediatismo da língua, marca também Mais cotidiano que o cotidiano, de Pucheu (2013) - como lê-se já no título. Ali, os arranjos aludidos por Caio Meira/Pucheu grassam, com poemas construídos a partir de transcrições mais diversas: falas ouvidas ou lidas, trechos de filmes, posts de redes sociais, cartas de assassinos, trocas de e-mails e até mesmo a transcrição de uma fala em uma banca de avaliação de pósgraduação. Ainda que os arranjos guardem o pudor de identificar (mesmo que de modo vago) as fontes de sua apropriação, parece haver uma grande fragmentação no procedimento, cindindo em partículas ainda menores e mais heterogêneas os discursos captados, em um esforço de apresentá-los como uma tapeçaria do cotidiano aludido.

De modo ainda mais anárquico, sucedem-se os fragmentos a compor o Livro das passagens, de Carlito Azevedo (2016), segunda parte do livro homônimo, que sucede um longo poema "autoral", e passa a misturar o registro da escrita com informações retiradas do feed do Facebook, fotos em redes sociais, conversas por aplicativos, diálogos de filmes, citações de outros poemas etc. Aqui, estes textos híbridos, análogos aos arranjos, mas também contrário a estes, não registram suas origens, apenas intuídas pelo leitor a partir de algumas marcações: visuais, editoriais ou até mesmo semânticas.

Parando um momento a observar este cenário, é possível elencar algumas características comuns a esses textos, a delinear um procedimento específico, para usarmos o termo de César Aira (2007): o dispositivo artístico de vanguarda, elegido para "fazer texto", para escrever sem escrever. Todos se constroem majoritariamente (ou, no caso de Delírios de Damasco ou dos arranjos de Pucheu, integralmente) por citações, 
trechos tomados de outras fontes, e reconhecem-se como tal, marcando na própria constituição o uso desse artifício poético. Como já dito aqui, isso corresponde ao programa mais amplo da apropriação contemporânea, delineada por Perloff (2013), e passível de um resumo bruto nas palavras (elas já, apropriadas ${ }^{3}$ ) de Kenneth Goldsmith (2011, n. p.): “O mundo é cheio de textos, mais ou menos interessantes; eu não quero adicionar mais nenhum".

Essa citação encaminha-nos também a pensar como tais procedimentos poéticos dialogam com a veia arquivística da apropriação: trata-se de uma poética de reciclagem, dedicada a enfrentar a desordem do mundo por meio da organização de suas matérias. Lê, com precisão, esse movimento o estudo de Leonardo Villa-Forte (2019, p. 60): “A literatura por apropriação opera como uma reação ao excesso de textos - e de discursos, de imagens etc. - do mundo. [...] Ao realizar o gesto da apropriação, um escritor aceita que esse contexto é uma realidade, e reage: a massa pesada não nos calará; pelo contrário, nós falaremos com ela". Essa apropriação reativa, poderíamos dizer, está no cerne da operação do arquivamento, como descrita por Brian Brothman (2018): a criação de um espaço organizacional que recorta certo conteúdo de seu contexto original caótico, e o salvaguarda dos ruídos, da própria entropia.

Vejamos isto operando nos livros em questão: quando Stigger afirma querer compor uma "arqueologia do presente", explicita o propósito de ler a linguagem solta como matéria para uma investigação material; e que, no seu caso, versa sobre a intolerância do cotidiano. Em ensaio sobre a produção do livro, afirma: "Acredito que certo momento da nossa sociedade está inscrito nessa sequência de frases. [...] Outras, no entanto, são obviamente terríveis, na medida em que colocam a nu aquilo que

3 A afirmação, como coloca já o próprio Goldsmith, é um desvio de uma citação do artista Douglas Huebler, acerca da arte conceitual (movimento ao qual Goldsmith associa sua Escrita Não Criativa): "The world is full of objects, more or less interesting; I do not wish to add any more".

4 No original: "The world is full of texts, more or less interesting; I do not wish to add any more". 
as pessoas gostariam que permanecesse escondido no âmbito privado" (STIGGER, 2013, n.p., grifos nossos). Freitas, a seu modo, age no mesmo sentido, compilando definições esparsas, nascidas da massa amorfa do senso comum, e organizando-as em um discurso artístico, que acaba por explicitar as marcações ideológicas prévias.

Essa operação, porém, se nos atermos às considerações sobre o arquivo, é tanto a leitura desses problemas nos materiais dos quais se parte, quanto a composição de uma nova textualidade, noutro espaço, que produz efeitos singulares, distintos daqueles "originais". Lemos isso na compreensão de que o arquivista age pela criação de valor no seu movimento ordeiro:

O trabalho de avaliação não é meramente um processo de identificação de valor, mas de criação ou destruição de valor [...] Ao decidirem a respeito do valor arquivístico ou histórico, os arquivista efetivamente criam, inauguram ou perpetuam um compromisso axiológico que se manifesta na permanência da ordem que daí resulta (BROTHMAN, 2018, p. 89-90).

Vemos tal trabalho nas composições singulares (a justaposição das frases em pequenos haicais, no caso de Stigger; a forma poema e a disposição particular em Freitas), e também no próprio fato de recolher estes fragmentos ao interior do sistema literário, por meio de mecanismos como a assinatura, como aponta Villa-Forte (2019, p. 46). O gesto arquivista é tanto mais aparente nos arranjos de Pucheu (2013), também: ao compilar trechos de manifestos terroristas, produz o poema Arranjo para tornar o mundo cada dia pior e mais violento (antivoz). Na sequência, elenca o nome das vítimas daqueles mesmos assassinos, sob o título de Arranjo para tornar o mundo cada dia menos violento (pós-voz). As vozes dos outros, tantas, tão confusas, são prefixadas, catalogadas. Não se adicionam à realidade, mas a modula, e o comentário crítico emerge dessa 
movimentação.

O valor é produzido pelo arquivista; pelo poeta, que assume o papel do antigo arconte, ${ }^{5}$ figura central ao conceito de arquivo, como lembra Jacques Derrida (2001). Assim, tomar tais apropriações como escritas arquivísticas nos auxilia a analisar não só as formas de composição dessa poesia mas também a construção de seus arranjos incide sobre uma compreensão da linguagem no mundo. Tal postura não seria exclusividade da poesia contemporânea; em verdade, ela remete-se à tradição da apropriação da literatura brasileira, no que ela tem de fundador à estética do país. Falamos da Antropofagia, por exemplo, que postulava já seu interesse na seleção do alheio, para uma deglutição (um arquivamento corpóreo, poderíamos dizer, sobrepondo as imagens deste ensaio) criadora. No Manifesto Antropófago, de 1928, fundação dessas perspectivas, encontramos a formulação essencial a tal visão da escrita: "Só me interessa o que não é meu. Lei do homem. Lei do antropófago" (ANDRADE, 1978, p. 13). Isso nos ajuda a entender, também, como a origem de um arquivo é sempre outro arquivo: aquilo do que se parte para roubar já é um conjunto mais ou menos organizado, com uma ordem e um valor singulares, por mais amplos que estes possa ser. No caso da antropofagia, por exemplo, rearquiva-se, segundo outra estrutura, o arquivo da cultura estrangeira; no caso, ainda mais vasto, das poéticas de apropriação, o que se vai catalogar e registrar sob critérios singulares é o arquivo do que for alheio. Podemos vê-lo com mais clareza em um exame das obras de Goldsmith, sempre localizadas na transcrição de objetos de cultura bastante circunscritos: a edição de um dia do The New York Times (2003) ou a transmissão de um único jogo de baseball (2008), por exemplo. Até Capital (2015), sua obra mais heterogênea, opera esta espécie de arquivamento duplo: mira um arquivo singular (textos que, de alguma forma, falam de Nova York)

5 O nome resgata a classe política que, na Grécia antiga, era responsável por resguardar documentos oficiais em sua casa, chamada arkheîon: princípio da ideia mesma de arquivo. 
e o reconstitui segundo uma estrutura arquivante própria (o método de colagens de Walter Benjamin).

Aí chegamos novamente ao nó identificado na poesia brasileira contemporânea em questão aqui: não apenas ela se interessa pelo que não é seu e o recorta de um fundo para iluminar suas nuances. Ela se interessa pelo que não é de ninguém - pelo ruído.

Quando Azevedo escreve seu Livro das postagens como quem rola um feed de rede social, parece haver uma preocupação distinta da marcação política antropofágica - e mesmo um descolamento da apropriação crítica advogada por Goldsmith que, ao singularizar uma textualidade outra para desapropriá-la, mostra como suas marcações de posse são instáveis. Aqui, trata-se de partir de uma fronteira já esfumada:

B: Tá foda. Tem um jornalista canadense todo arrebentado. E agora bateram no carinha da Mídia Ninja. Bateram muito. Quebraram o equipamento dele.

P: Caralho. Todos os que estamos fora da Praça temos que mobilizar as autoridades. É caso de urgência.

B.: Estou aqui online, P., vamos dividir as ações. Já ligou para quem?

P: Eles batem e riem.

E.: A Praça Saens Peña está sitiada agora, com manifestantes gravemente feridos (braços quebrados, cortes profundos) e não chega ajuda médica. Ninguém entra e ninguém sai. Se alguém morar na Praça ou conhecer algum médico (*) que mora por aqui é importante ajudar! Policiais dispersaram com bombas um grupo com cerca de 300 manifestantes que tentou se aproximar do Maracanã (AZEVEDO, 2016, p. 67)

Nesses tempos, tal trecho, ainda que conte com certa especificidade 
dos eventos narrados, poderia ser encontrado em qualquer lugar de nossa experiência imediata de informação; conversa colhida de uma transmissão ao vivo, thread de Twitter, transcrição de uma conversa no WhatsApp? É justo essa impossibilidade de determinação da coleta (mas que permanece, ainda, sendo uma coleta, uma apropriação; é sua diferença da mera ideia de "inspiração"), sua "inespecifidade” que marca essa poética; e a leva à impertinência, para recuperarmos o termo de Garramuño (2014), no sentido de que escreve com o que não pertence a ninguém. $\mathrm{O}$ valor encontrado na desordem do mundo é, contraditoriamente, o do ruído, do lixo discursivo. Esses poetas passam a registrar no arquivo o que seria uma espécie de repertório comum.

\section{Do repertório ao arquivo e de volta outra vez: a apropriação em curto- circuito poético}

A distinção entre arquivo e repertório é o motor do livro homônimo de Diana Taylor (2013). Ali, a teórica desenvolve seus estudos sobre a performance como episteme. Se suas questões gerais distam das nossas, recuperamos esse par conceitual no que ele pode nos auxiliar a entender a distinção do procedimento em foco neste ensaio - bem como este procedimento parece oferecer uma resposta singular ao dualismo sustentado por Taylor.

Trata-se, de saída, de uma oposição. Seu argumento em favor do poder epistemológico das performances liga-se a uma leitura crítica da tradição logocêntrica do pensamento, focado no conhecimento materializado em documentação. Parte-se sempre do arquivo, diz. A esta postura, contrapõe a necessidade de nos acercarmos do repertório, entendido como uma espécie de repositório intangível da cognição performática: 
O repertório, por outro lado, encena a memória incorporada - performances, gestos, oralidade, movimento, dança, canto -, em suma, todos aqueles atos geralmente vistos como conhecimento efêmero, não reproduzível. [...] O repertório requer presença - pessoas participam da produção e reprodução do conhecimento ao "estar lá", sendo parte da transmissão (TAYLOR, 2013, p. 49-50).

Nessa leitura, podemos entender que tal linguagem do cotidiano aludida pelos livros em questão, por eles envolvidos, seria da ordem desse repertório, na medida em que se configura (pretensamente) imediata, espontânea - e, assim, carregaria um conhecimento distinto. Podemos depreender que é essa a compreensão dos poetas em questão: quando Stigger (2013), por exemplo, afirma as frases coletadas como o desvelar de uma pulsão oculta no social; quando lemos o machismo virtual capturado por Freitas (2012) ou o desassossego real demonstrado por Azevedo (2016). Afinal, “as performances funcionam como atos de transferência vitais, transmitindo o conhecimento, a memória e um sentido de identidade social" (TAYLOR, 2013, p. 27).

$\mathrm{O}$ que se tentaria arquivar, portanto, é esse imaterial, o conhecimento bruto no coração da linguagem automática, impensada, que nos cerca a todo momento. Entretanto, a própria Taylor (2013, p. 51) concede que há algo nas performances que escapa a tal cognição imediata: "As performances também replicam a si mesmas por meio de suas próprias estruturas e códigos. Isso significa que o repertório, como o arquivo, é mediado". Esta mediação se daria por processos de seleção e memorização, que distariam, segundo Taylor, dos processos de arquivamento por serem ainda imateriais; pense-se na ideia da memória oral dos contadores de histórias em sociedades ágrafas e entre povos originários.

Em um primeiro passo, para nos distanciarmos da dicotomia "língua x fala" que essa categorização oferece, mas ainda atentos ao que 
ela apresenta de potente para pensar a relação entre estes polos, propormos pensar a poesia como um lócus possível a essa forçosa mediação do performático, da linguagem-em-processo - mediação iniciada pelo gesto apropriacionista, aliado aos procedimentos específicos do fazer poético. Lembremos como Villa-Forte (2019) analisa a interposição das assinaturas em Delírio de damasco e Um útero é do tamanho de um punho como dispositivos de deglutição, pelo literário, do bruto anônimo. Poderíamos, então, pensar outros elementos da escrita literária como tal, enquanto agentes de arquivamento destas performances, como a disposição em versos dos fragmentos, originalmente em fluxo de discurso, como é mais flagrante em Freitas (2012) e Azevedo (2016); ou a unidade temática interna aos arranjos e a sua justaposição em seções do livro, gerando um discurso geral, como em Pucheu (2013). São ferramentas do literário, de saída entendidas como um método de arquivamento, mas aqui dedicadas à reprodução de performances; agindo como intermediárias de um repertório.

Assim, vê-se que a apropriação não se comporta em um esquema conceitual rígido, dualístico: pelo contrário, interessa-nos ver como essa literatura subverte tais compreensões. Para tanto, podemos ir a outro livro de apropriação, próximo aos já citados aqui: em Sessão, de Roy David Frankel (2017), recolhem-se os discursos dos deputados federais durante a sessão de votação do impeachment de Dilma Roussef, em 2016. Tais falas são apresentadas organizadas enquanto poemas, com seu texto solto, livre das marcações institucionais originárias. Viram versos, como: Meus filhos nunca / quiseram que eu / entrasse na política, e a maioria / dos corintianos /também não; mas, infelizmente, /entrei. /Que decepção! / Meu voto é não.” (FRANKEL, 2016, p. 93).

Sessão opera de modo diferente de Livro das postagens e Delírio de damasco no que não captura a "linguagem do agora" anonimizada: opera uma lógica inversa, transcrevendo discursos altamente historicizados, documentados em notas taquigráficas: um arquivo institucional, dos mais 
tradicionais. Se nossa poesia-objeto até aqui arquivava um repertório, especulemos que Sessão passa a performar um arquivo. Performance, sim, mesmo ele sendo um livro (e, portanto, um arquivo), na medida em que seu procedimento (sua provocação, marca forte do performático) se dá pela manipulação dos discursos políticos, que passam a ser destituídos de suas marcações de enunciação (não há identificação dos interlocutores) e têm sua massa heterogênea, conflituosa, submetida à enunciação poética, reunidos sob a mesma rubrica (o poeta Frankel), enunciados a um só tempo - entendemos esse gesto como performático pela lente epistêmica da performance, como advoga Taylor (2013, p. 27).

Com esta volta no parafuso operada em Sessão queremos avaliar que a abertura dessa possibilidade de transferência inversa à apropriação leva a pensar no entrecruzamento entre arquivo e repertório no exercício da linguagem, tema que movimenta essa poesia - entrecruzamento que operaria, enquanto metonímia da indistinguibilidade entre próprio e alheio na escrita, preocupação de fundo de toda a poética não original.

Na escrita, mesmo que ela seja, de saída, uma espécie de suplemento necessário, dedicada ao registro e o acúmulo, não há escape possível à já mencionada entropia da significação, à linha de fuga dos sinais - a escrita é tão efêmera quanto mais arquivística for, em um paradoxo que move sua poética. De certo modo, os arquivos apropriacionistas de Delírio de damasco, Um útero é do tamanho de um punho, Mais cotidiano que o cotidiano e Livro das postagens acabam seguindo o caminho de Sessão e veem seu acúmulo se erodir em performance de novo, na medida em que o texto poético abre um jogo. Assim, o que a apropriação realiza é, mais do que um comentário crítico localizado (uma concepção ainda moderna das artes da cópia e da reescrita),uma reflexão mais ampla sobre a linguagem e suas impermanências e impertinências. Essa ideia de uma erosão do livro-apropriacionista lê-se de modo preciso na reflexão de Stigger (2013) sobre seu trabalho, visto que afirma uma vontade de "devolver à rua" os 
fragmentos dela retirados - como se Marcel Duchamp um dia resolvesse andar de novo em sua Roda de bicicleta. Tarefa impossível, vê-se; e Stigger o percebeu também ao apresentar o trabalho a alguns amigos e conhecidos de quem havia tomado palavras: "A primeira providência foi passar para o computador todas aquelas frases que lembrava de memória. [...] O curioso é que as pessoas que pronunciaram essas frases não se lembravam de tê-las dito, enquanto eu nunca as esqueci (STIGGER, 2013, n.p., grifos nossos)".

Dois elementos a a serem articulados aqui. O primeiro está no fim: a ação deste segundo sujeito que surge, não apenas os performers originários, mas também o poeta que nunca esquece. Arconte zeloso, ele consegue entrever, em meio à desordem dos tantos textos no mundo, uma forma, que salvaguarda. Ao reinscrevê-la (que é, de fato, escrevê-la), porém, percebe a incapacidade de retorno das performances ao repertório primeiro, após seu processo de mediação pela poesia. As frases não podem retornar às ruas pois passaram pelo processo de marcação artística da apropriação, que parece não mudar nada, mas opera uma violenta ação tradutória: transforma a desordem natural dos ruídos, sua crueza que a valida como performance imediata, em valor arquivístico, artístico.

Isso nos encaminha a considerar a apropriação dessa poesia como construída sobre um mal de arquivo - que Derrida lê tanto como uma febre, uma ânsia de arquivamento ("sofro do mal de arquivo, preciso organizar o mundo"), mas também como a pulsão interna ao arquivo, mal no arquivo, de contínua desintegração de seu caráter monumental:

Diretamente naquilo que permite e condiciona o arquivamento só encontraremos aquilo que expõe à destruição e, na verdade, ameaça de destruição, introduzindo a priori o esquecimento e a arquiviolítica no coração do monumento. No próprio "saber de cor". O arquivo trabalha sempre $a$ priori contra a si mesmo (DERRIDA, 2001, p. 23).

O que seria tal escrita apropriacionista senão a exibição de um 
saber de cor? (E o que a enunciação desta memória senão justo o conceito de performance?). Stigger decora as frases, bem como Pucheu a ouvir as palavras dos vendedores no trem, na gênese de seus arranjos, ou como Azevedo diante do frenesi de um feed e de uma biblioteca (Freitas, poderíamos dizer, se vale de um "decorador" intermediário, encarnado no algoritmo de pesquisa). E o que seria o saber de cor, senão uma segunda dissolução? Na direção do quê? Das palavras, sempre: "Havia apenas as palavras lidas e as palavras ouvidas e as palavras reproduzidas na escrita." (PUCHEU, 2013, p. 53). O que não quer dizer da possibilidade de uma linguagem comum, pura; justo o avesso. Parte-se do já vincado e devolvese a ele uma linguagem ainda mais contaminada; decorada, no duplo sentido do termo.

$* * *$

À guisa de um final, na esteira destas considerações breves, de uma escrita em movimento, voltamos ao Perfil parcial de um procedimento de Caio/Alberto/Meira/Pucheu. Esse texto parece, assim, demarcar o que chamamos de especificidade do inespecifico da cena poética descrita aqui: o uso intensivo de uma apropriação da linguagem cotidiana, que, manipulada à título de registro (como se lê nas tantas referências a uma arqueologia feita por tal poesia), acaba por dar em uma tradução distinta, tanto marcada pelo gesto artístico-arquivístico do poeta-arconte (se não autor, para evitarmos o termo gasto, algum tipo de interventor) quanto pela dinâmica da própria língua, necessariamente mediada, que rompe a dicotomia entre suas expressões privado e pública.

É menos a invenção de um "ele lírico", para lembrarmos o termo de Meira/Pucheu, e mais a sua performance, na medida em que encarna o papel, mas não se deixa de ser, de certo ponto, o "eu lírico". Ainda se escreve, com as marcas de um registro que é forçosamente individual, 
particular - próprio. Contudo, ao lançar-se nesta escrita, tentando fugir das próprias marcas, localizando na linguagem comum um campo aberto para que a apropriação grasse, acaba-se por rechaçar o arquivamento apenas de valores positivos: decora-se também o lixo e o ruído, por sua capacidade de embaralhar as transações entre mundo e texto.

Afinal, os sujeitos são sempre líricos, e a poesia tem a ver com fazer parar o coração do monumento.

\section{Referências}

AIRA, César. Pequeno manual de procedimentos. Curitiba: Arte \& Letra, 2007.

AZEVEDO, Carlito. Livro das postagens. Rio de Janeiro: 7 Letras, 2016.

BROTHMAN, Brian. Ordens de valor: questionando os termos teóricos da prática arquivística. In: HEYMANN, Luciana; NEDEL, Letícia (Org.). Pensar os arquivos. Rio de Janeiro: FGV Editora, 2018.

DERRIDA, Jacques. Mal de arquivo: uma impressão freudiana. Rio de Janeiro: Relume Dumará, 2001.

FRANKEL, Roy David. Sessão. São Paulo: Luna Parque Edições, 2017.

FREITAS, Angélica. Um útero é do tamanho de um punho. São Paulo: Cosac Naify, 2012.

GARRAMUÑO, Florencia. Frutos estranhos: sobre a inespecificidade na estética contemporânea. Rio de Janeiro: Rocco, 2014.

GOLDSMITH, Kenneth. Capital: New York, Capital of the 20th Century. Londres: Verso, 2015.

GOLDSMITH, Kenneth. Day. Great Barrington: The Figures, 2003.

GOLDSMITH, Kenneth. Sports. Los Angeles: Make Now, 2008. 
GOLDSMITH, Kenneth. Uncreative writing: managing language in the digital age. Nova York: Columbia University Press, 2011. Edição digital para Kindle.

KLINGER, Diana. Poesia, documento, autoria. Estud. Lit. Bras. Contemp., Brasília, n. 55, p. 17-33, dez. 2018. Disponível em: http://www.scielo.br/scielo.php?script=sci_arttext\&pid=S231640182018000300017\&lng=en\&nrm=iso. Acesso em: 10 jun. 2020.

MANZONI, Filipe. Memes, poemas e algumas suspeitas sobre o não original. eLyra, n. 13, p. 115-136, jun. 2019. Disponível em: https://elyra. org/index.php/elyra/article/view/283 Acesso em: 12 jun. 2020.

PERLOFF, Marjorie. O gênio não original: poesia por outros meios no novo século. Belo Horizonte: Editora UFMG, 2013.

PUCHEU, Alberto. Mais cotidiano que o cotidiano. Rio de Janeiro: Beco do Azougue, 2013.

STIGGER, Veronica. Delírio de Damasco. Florianópolis: Cultura e Barbárie, 2012.

STIGGER, Veronica. Pré-histórias: uma arqueologia poética do presente. Revista Z Cultural, Rio de Janeiro (UFRJ), v. VIII, n. 3, 2013. Disponível em: http://revistazcultural.pacc.ufrj.br/pre-historias-uma-arqueologiapoetica-do-presente-deveronica-stigger/. Acesso em: 12 jun. 2020.

SUSSEKIND, Flora. Objetos verbais não-identificados, Prosa \& Verso, Jornal O Globo, 21/9/2013. Disponível em <http://oglobo.globo.com/ blogs/prosa/posts/2013/09/21/objetos-verbaisnao-identificados-umensaio-de-flora-sussekind-510390.asp>. Acesso em: 10 jun. 2020.

TAYLOR, Diana. $O$ arquivo e o repertório: performance e memória cultural nas Américas. Belo Horizonte: Editora UFMG, 2013.

VILLA-FORTE, Leonardo. Escrever sem escrever: literatura e apropriação 
no século XXI. Rio de Janeiro: Ed. PUC-Rio/ Belo Horizonte: Ed. Relicário, 2019.

Recebido em: 30/05/2020

Aprovado em: 26/06/2020 